University of Nebraska - Lincoln

DigitalCommons@University of Nebraska - Lincoln

Faculty Publications, Department of Psychology

Psychology, Department of

$1-30-2004$

\title{
Understanding mental health needs of Southeast Asian refugees: Historical, cultural, and contextual challenges
}

\author{
Eugenia Hsu \\ University of Nebraska-Lincoln \\ Corrie A. Davies \\ University of Nebraska-Lincoln, cdavies2@unl.edu \\ David J. Hansen \\ Univertsity of Nebraska-Lincoln, dhansen1@unl.edu
}

Follow this and additional works at: https://digitalcommons.unl.edu/psychfacpub

Part of the Psychiatry and Psychology Commons

Hsu, Eugenia; Davies, Corrie A.; and Hansen, David J., "Understanding mental health needs of Southeast Asian refugees: Historical, cultural, and contextual challenges" (2004). Faculty Publications, Department of Psychology. 86.

https://digitalcommons.unl.edu/psychfacpub/86

This Article is brought to you for free and open access by the Psychology, Department of at DigitalCommons@University of Nebraska - Lincoln. It has been accepted for inclusion in Faculty Publications, Department of Psychology by an authorized administrator of DigitalCommons@University of Nebraska - Lincoln. 


\title{
Understanding mental health needs of Southeast Asian refugees: Historical, cultural, and contextual challenges
}

\author{
Eugenia Hsu, Corrie A. Davies, and David J. Hansen \\ Department of Psychology, University of Nebraska-Lincoln \\ Submitted September 2001; revised September 2003; accepted October 2003
}

\begin{abstract}
Research and clinical information pertaining to mental health needs of Asians residing in the United States is limited but growing. There is a tendency to group all persons of Asian descent together and, therefore, the empirical literature does not sufficiently address the mental health needs in specific subgroups. The focus of this article is to understand the mental health needs of one subgroup of Asians-Southeast Asian refugees (SEAR). The main purpose is to review the relevant literature pertaining to Southeast Asian refugees' experiences and to understand the manifestation of psychiatric disorders by examining historical, cultural, and contextual challenges. Despite the well-documented mental health needs for SEAR, most do not present for mental health services. Therefore, resilience and protective factors are discussed. Research and clinical implications are described and suggestions are offered on how to apply information obtained from Southeast Asian refugees' experiences to future refugees.
\end{abstract}

Keywords: Mental health, Southeast Asian, Refugees, Cultural issues, Protective factors

\section{Introduction}

Asians are a diverse population encompassing members of as many as 40 distinct cultural subgroups (Sandhu, 1997). Psychologists have primarily studied Asian groups from Cambodian, Chinese, Filipino, Hmong, Japanese, Korean, Lao, Mien, and Vietnamese ancestry. Due to the increased necessity to consider mental health needs, given their shared common experience of war-induced trauma and significant stressors related to migrating to a foreign country, the focus in this review is on one subgroup: 
the Southeast Asian refugees (i.e., Cambodian, Vietnamese, Hrnong, and Laotian). Research currently focusing on mental health needs of Southeast Asian refugees (SEAR) is minimal despite the documentation that the need exists.

Available data indicate that a large number of SEAR have resettled in the United States. For instance, it has been estimated that between 800,000 and one million SEAR were residing in the United States between 1975 and the early 1990s (Chung \& Lin, 1994; Morrow, 1994). In 1989 alone, 106,902 refugees were admitted into the United States, with 42.8\% from Southeast Asia, 36.9\% from the Soviet Union, and the remaining 20.3\% from other parts of the world (Eastern Europe, Near East, Africa, and Latin America; Office of Refugee Resettlement, 1990). The Refugee Act of 1980 defines refugees as "someone who has a well-founded fear of being persecuted in their homeland, for reasons of their race, religion, nationality, social group or political opinion" (Vu, 1990, p. 234). During the first 2 years of their residence, refugees live under a "parole" status and are allowed to apply for legal alien resident status after that duration (Kessner \& Caroli, 1982). Public assistance is typically needed for newly migrated refugees to allow them some time to adjust culturally and emotionally to the new environment $(\mathrm{Vu}, 1990)$. Therefore, refugees enter the United States under conditions that affect their readjustment to the new country.

Asian refugees residing in the United States can be differentiated based on the country in which they were born as well as the conditions in which they left their native countries (i.e., as immigrants or refugees). Since refugees enter the United States under significantly different conditions than immigrants, the distinction between immigrants and refugees is important in this area of research to further delineate experiences of SEAR. Kunz (1973) described the kinetic model to explain flight of immigrants and refugees. Refugees are described as being "pushed out" of their native country (i.e., to seek asylum from traumatic conditions in countries of origin). Alternatively, immigrants are described as being "pulled away" from their home country to the resettlement country. Therefore, immigrants are "pulled toward" the new country because they are attracted by the opportunities they perceive are available (e.g., better standard of living, better jobs, and education). Thus, the motivation for migrating differs between immigrants and refugees (Westermeyer, 1990). Another distinction is the option to return to their homelands; immigrants have the option of returning to their countries of origin whereas refugees generally cannot return to their native countries (Westermeyer, 1990).A further key distinguishing factor between immigrants and refugees is whether the individual's decision to move to another country was voluntary (i.e., immigrants) or involuntary (i.e., refugees). Since refugees are typically pushed out of their homelands (Kunz, 1973), they are often unprepared for circumstances ahead of them that may result in feelings that they have little or no control (Pemice \& Brook, 1994). Refugees, therefore, feel they are losing control, while immigrants feel they are gaining control of their future during the migration process (Westermeyer, 1990). Lastly, refugees are distinctly different from immigrants due to the circumstances precipitating their migration (e.g., loss, violence, camps, political pressure to leave their native country), the events that occur during the migration, and the situations after their migration (e.g., unemployment, separation from family, racism).

Although SEAR have commonly been categorized as one group due to their shared similar characteristics and experiences, differences do exist. SEAR represent a wide range of ethnic, linguistic, and religious groups. Additionally, occupation and education levels vary within these groups. For instance, the Hmong and Cambodians are less educated, and reported the lowest level of literacy in their own language and English compared with Laotians and Vietnamese (Chung \& Lin, 1994). Furthermore, Hmong and Cambodians have had the least exposure to Western ideas and concepts in their native countries in contrast to Vietnamese and Laotians (Chung \& Lin, 1994). Mattson (1993, p. 156) 
has described two waves of Southeast refugees: "the earlier refugees tended to be university educated, wealthy, and influential in their homelands whereas the second wave (the boat people) were often illiterate in their own languages, were unfamiliar with Western technology, and lived on a subsistence level (most were families of farmers and/or fishermen from rural areas)."

Refugees from other countries continue to seek refuge and resettle in the United States. When refugees arrive to the United States, various disciplines including mental health professionals, attempt to assist them during the readjustment period. The focus of this article is to understand the mental health needs of SEAR by reviewing the relevant literature. In addition to exploring historical and contextual challenges encountered by SEAR, it is equally important to understand when common Asian cultural values are challenged. Mental health needs are well documented for SEAR; however, most refugees do not present for mental health services. Therefore, resilience factors are also discussed, as they appear to protect SEAR against mental health problems. Based on the research and clinical implications that are described, recommendations are made on how to apply information obtained from Southeast Asian refugees' experiences to future refugees.

\section{Historical considerations}

Before proceeding with the discussion on mental health issues and research related to SEAR, it is important to consider the historical context that brought SEAR to the United States. Abueg and Chun (1996) identified multiple stressors experienced by SEAR including those related to migration and encampment. Many Southeast Asians endured government-sponsored intimidation and threats to their lives once the Communists gained control of their homelands in Vietnam, Cambodia, and Laos (Abueg \& Chun, 1996). Migration stressors include separating from or witnessing deaths of family and relatives while fleeing one's home country under life-threatening conditions (Abueg \& Chun, 1996; Boehnlein \& Kinzie, 1997). After SEAR escaped their native countries, they experienced additional stressors. For example, many refugees experienced assaults by border guards while entering neighboring countries (Abueg \& Chun, 1996; Boehnlein \& Kinzie, 1997). While residing in refugee camps, encampment stressors included extended detainment in unsafe, overcrowded, and poorly sanitized environments (Abueg \& Chun, 1996). During their detainment, many refugees also faced uncertainty surrounding their future and the fate of separated family and friends (Abueg \& Chun, 1996). Research has shown that SEAR are at a risk for developing psychiatric illness due to their experience of leaving their native country and memories related to brutal war, escape, or concentration camp experiences (Abueg \& Chun, 1996; Boehnlein \& Kinzie, 1997). Although there are common premigration stressors that most SEAR experienced, each of the SEAR subgroups also encountered its own unique set of refugee circumstances.

\subsection{Cambodian refugees}

Cambodian refugees who survived the Khmer Rouge era (1975-1979) witnessed more than one million Cambodians die of disease, starvation, or execution (e.g., killings and torture of Buddhists monks and professionals; Kinzie, 1989). Mass execution, forced separations of family members, and confinement of work camps were particularly targeted at the professional and working classes during the Pol Pot regime to establish a Marxist agrarian society and demolish any Western influence (Abueg \& Chun, 1996). Children were often separated from their parents, who were forced to work in agricul- 
tural labor camps (Kinzie, 1989). The work camp environment included hard labor, torture, beatings, starvation, disease, and killing (Abueg \& Chun, 1996). After the 4 years of Pol Pot, the Vietnamese invaded Cambodia in 1979. Many Cambodians became refugees at that time escaping to Thailand, then later to another country, usually the United States, France, or Australia (Kinzie, Boehnlein, \& Sack, 1998). These invasions affected the essence of Cambodian life and society.

\subsection{Vietnamese refugees}

The Vietnamese refugees can be described in two waves. Beginning in 1975, first-wave Vietnamese refugees migrated to the United States primarily in family units and represented the educated and professional classes of Vietnam (Abueg \& Chun, 1996). In contrast, second-wave Vietnamese refugees who fled Vietnam between 1977 and 1980 were mostly of rural and less educated backgrounds. This latter group was referred to as the "boat people" (Abueg \& Chun, 1996). The second-wave Vietnamese refugees endured severe migration traumas. It is estimated that more than 200,000 of these refugees died at sea as they fled Vietnam on overcrowded and outdated vessels (Lee \& Lu, 1989; Mollica, 1994). Furthermore, more than $80 \%$ of the boats were boarded by pirates who robbed, raped, assaulted, and killed its passengers (e.g., Lee \& Lu, 1989; Mollica, 1994). Those who succeeded in fleeing Vietnam mostly landed in refugee camps in Thailand, often considered to have the worst camp conditions. Other camp locations included Hong Kong, Indonesia, Malaysia, and the Philippines. During the Vietnamese refugees' residence in these camps, the refugees endured additional stressors such as overcrowding, starvation or poor nutrition, unsanitary conditions, and personal danger (Abueg \& Chun, 1996; Beiser, Turner, \& Ganesan, 1989; Mattson, 1993). These camp conditions varied from country to country. In one survey of 81 Vietnamese refugee patients, the following major traumas were reported: escaping by boat without adequate food or water $(16 \%)$, being attacked by pirates $(9.6 \%)$, being raped during flight $(6.5 \%)$, and witnessing a relative or friend killed in the camps or in war $(9.6 \%$; Flaskerud \& Anh, 1988).

\subsection{Laotian and Hmong refugees}

The Laotians and Hmongs also had experiences similar with the Cambodians and Vietnamese refugees. In 1979, Pathet Lao seized control of Laos, and thousands of Laotians of diverse social, educational, and economic backgrounds escaped to the adjacent country of Thailand, where almost all were detained in refugee camps (Abueg \& Chun, 1996). Hmong and Mien cultures were also affected since they are rooted in tribal, agrarian, and preliterate societies located in the mountainous regions of Laos and other Southeast Asian countries (Abueg \& Chun, 1996).

\section{Cultural and contextual considerations}

\subsection{Cultural values}

To obtain a complete picture of mental health needs of SEAR, mental health problems must be examined within a cultural context. Cultural factors are important because they affect the individual's subjective perceptions of both the traumatic experience and the adaptation process. Specific cultur- 
al values such as family structure, gender roles, attitudes about sexuality, and fatalism and karma are likely to affect the mental health of SEAR and should be taken into consideration when conceptualizing the events experienced by SEAR.

\subsubsection{Family structure}

The family is the primary social unit in Asian cultures and a source of strong identity for its members. Roles and positions of hierarchy are evident in traditional Asian families (e.g., Ho, 1990; Lee, 1996; Shon \& Ja, 1982; Uba, 1994). Specifically, elders are placed in roles of authority and men are considered to be higher on the hierarchy than women. The father is considered the leader and authority of the family whereas the traditional mother is the primary caregiver of the children and the household (Futa, Hsu, \& Hansen, 2001). Children also have specific roles in the family such that they are expected to abide to filial piety (i.e., have unquestioning respect for parents, grandparents, and other elders; Ho, 1990). In the absence of the father, the oldest son assumes the role of head of the family (Shon \& Ja, 1982).

These traditional values of SEAR were affected by trauma endured in the native country and the migration to another country. The possible effects of trauma on a person (e.g., depression, irritability, hypervigilance, startle reaction, nightmares) can greatly impact an individual's ability to function in the family (Kinzie et al., 1998). Given the language barriers, and little or no formal Western education and vocational experience, elders lost their status within the family and the society (Kinzie et al., 1998). Due to the high rates of mate deaths during the Cambodian trauma, family structures have often changed (Kinzie et al., 1998). Single mothers taking over the responsibility as the primary caregiver and raising a family became more common. Children's roles were also altered. Children, became communication facilitators (i.e., guides and interpreters) between their parents and the mainstream society; therefore, reversing the traditional parent-child relationship. The language barriers also made it difficult for parents to assist their children with basic activities such as homework. This transfer of authority from elders to the young disrupted traditional cultural values and roles within the family structure (Kinzie et al., 1998).

\subsubsection{Gender roles}

In SEAR cultures, women are traditionally seen as inferior to men. Men are highly valued in Asian cultures; they are expected to financially support and control the family, whereas women are expected to be subservient, obedient, and quiet (Ho, 1990). Women's status relative to men is reflected in several cultural practices. For example, traditionally, higher education had been provided to men only, and women were discouraged from developing abilities or talents which would be useful for obtaining work outside the home (Ho, 1990; Tran \& Des Jardins, 2000).

These traditional gender roles of the SEAR cultures were challenged when resettling in the United States. Chung, Bemak, and Kagawa-Singer (1998) found that the unemployment or underemployment of refugee men resulted in women needing to find work to support their families. Although men have experienced downward mobility in employment, women have generally experienced increased occupational opportunities following migration to the United States compared with their employment status in Southeast Asia (Chung et al., 1998). These changes in gender roles have created conflict between familial values of their culture and those of the resettlement country and have placed severe pressure on traditional marriage and family relationships (Ito, Chung, \& Kagawa-Singer, 1997). 


\subsubsection{Attitudes toward sexuality}

One of the traditional Asian cultural values is sexual chastity before marriage and faithfulness to a woman's husband after marriage (Chan \& Leong, 1994). This traditional expectation of faithfulness applies to the wife. In general, sexuality is considered a taboo topic for discussion in Asian culture (Bhugra \& Cordle, 1988; Chan \& Leong, 1994). These views about sexuality are important, given that sexual assaults have been identified as one of three most severe forms of premigration traumas endured by Southeast Asian refugee women (Ito et al., 1997). Because trauma cannot be defined without considering the individual's sociocultural background through beliefs and attitudes the individual has acquired and internalized (de Silva, 1999), SEAR views regarding sexuality must be considered when examining the impact of rape on a Southeast Asian refugee woman.

According to Ito et al. (1997), women typically blame themselves for rape in Southeast Asian cultures and, therefore, they rarely seek help related to the sexual assault. For Southeast Asian women, rape is not only a personal violation that results in loss of self-respect, it is also a form of dishonor to the family (Ito et al., 1997). Society's reaction to the individual's traumatic experience is related to how the effects of the trauma will develop (de Silva, 1999). Examples of social consequences of rape in Southeast Asian cultures include community rejection, family disownment, and divorce (Ito et al., 1997). These negative social reactions can impact the victim's ability to share her experiences. Thus, Southeast Asian women who have experienced sexual assaults may not reveal their sexual traumas due to the severe social and cultural implications. Subsequently, victimized women may suffer in silence to maintain the secret from others.

\subsubsection{Buddhism: fatalism and karma}

Most Cambodian refugees follow Buddhism, a religion that encourages acceptance of losses, resignation to the suffering of life situations, little expectation for better times during one's lifetime, and dignified and moral behavior to ensure a better afterlife (Strober, 1994). Subsequently, most Cambodian refugees do not complain about their situations or blame others for their inability to adjust, do not share their sufferings with each other, and despite their difficulties, work hard and try to express an optimistic attitude (Strober, 1994). Fatalism is the acceptance of one's situation. Many Cambodians frame their traumatic experiences within their Buddhist belief and, therefore, life experiences are regarded as meaningful occurrences of fate or karma (Abueg \& Chun, 1996). Additionally, this fatalistic approach to one's present existence is also related to Buddhist teachings that a person controls his or her own destiny through free will and cannot escape present suffering in this world (Boehnlein, 1987).

Since many SEAR experienced torture, it is also important to evaluate the cultural perspective of torture. Mollica and Caspi-Yavin (1992, p. 256) described that "in Western society, the word torture is derived from the Latin word torquere, which means 'to cause to turn, to twist' to extract testimony and/ or evidence or to repress opposing religious or political views." Additionally, torture is associated with legal confessions and the political suppression of an individual's human rights. In contrast, in Cambodia, the word for torture--tieru na kam--is derived from the Buddhist term for karma. Karma is defined as the individual's actions or thoughts (often of an evil nature) in a prior existence that affects life in the present. The torture experience is "often believed by Cambodian survivors to be caused by bad actions (unrelated to the torture) and resulting karma" (Mollica \& Caspi-Yavin, 1992, p. 256). Therefore, Cambodians who are Buddhists believe that personal misfortune is inevitable and that current life stressors or failures depend upon actions of the previous life (Kinzie, 1989). However, these atrocities not only bring individual shame, they also represent national shame to Cambodians. Kinzie (1989) de- 
scribed Cambodian patients as believing that Cambodians must have done something very bad in the past to deserve this kind of punishment and torture. Therefore, Southeast Asian refugee patients not only have seen their family members killed, they also witnessed their culture being destroyed.

\subsection{Contextual factors}

In addition to examining historical and cultural factors, contextual factors must also be explored to obtain a complete picture of the mental health needs of SEAR. Various facets of acculturation stress should be considered when working with this population. Acculturation stress is the result of the challenges related to relocating and readjusting to a resettlement country. Challenges include expectations (e.g., find job, learn new language, adapt to new customs), socioeconomic and environmental stressors (i.e., poverty, area of residence), racial discrimination, and health care consequences (inaccessibility to services, cultural competence of providers). The impact of acculturation on educational attainment and ethnic and cultural identity are additional factors that are important to consider when working with SEAR.

Refugees encounter specific challenges as they leave their native countries and attempt to reconstruct the world they have lost in a new country. First, refugees will inevitably experience the sense of loss. The majority of SEAR have lost significant others (e.g., friends or family members) and are often not aware of the whereabouts of loved ones (Chung \& Lin, 1994). Not only do SEAR endure personal loss, they also face the loss of material belongings, the loss of their country, and the loss of a familiar way of life (Abueg \& Chun, 1996). As refugees enter into a new country, they are expected to find a job, learn a very different language, and adapt to new customs (Beiser, 1990; Chung \& Lin, 1994). SEAR are immersed in a context of a new and unknown culture where they lack familiar social support networks (including family) and lack the knowledge to access resources for economic self-sufficiency (Chung et al., 1998). These situations are highly demanding and are often not in direct control of the refugee; thus, refugees' emotional resilience and coping resources are challenged. If protective resources are insufficient, severe psychological distress may surface.

Southeast Asian women also encounter specific acculturation stress due to factors such as their low educational levels and limited job skills (due to inability to read, write, and speak in English). Additional examples of family stressors endured by SEAR women include having no extended family support, being single parents with no experience or role models to emulate, facing problems in role-reversal and shift of power when the woman is the wage-earner and the man stays at home, and finding childcare (not earning enough money to pay for daycare and having no extended family to care for children; Carlin, 1990). Furthermore, SEAR women may face challenges in obtaining assistance for medical problems including pregnancies (e.g., transportation problems, language problems, no medical insurance) and coping with overt or masked depression (Carlin, 1990).

Disciplinary techniques have also been identified as a potentially problematic area for mothers and children. Specifically, Southeast Asian mothers may need to find disciplinary methods that are acceptable in the Western culture. Examples of physical disciplinary techniques known to be utilized by Southeast Asians include making children kneel for hours or tying children's hands and feet together and making them sit in a corner all day (Carlin, 1990). These methods of disciplining children are considered to be unacceptable methods in the new country. Additionally, indigenous practices such as "cupping," coin rubbing, and moxibustion are traditionally used to heal minor illnesses; however, they can leave bruises or scars that can be misdiagnosed as child abuse (Canino \& Spurlock, 2000). 
"Cupping" involves placing a small heated cup on the skin. A vacuum is created between the cup and the child's skin as the cup is allowed to cool. This healing practice results in circular reddened areas to emerge. "Cia cio" or coin rubbing consists of rubbing warmed oil on the skin with a coin or spoon. This repetitive linear rubbing can cause symmetrical and linear bruises to appear (Canino \& Spurlock, 2000). Finally, moxibustion is a variation of acupuncture such that sticks of incense or other materials are burned near or on the skin at specific therapeutic points. This practice may result in the skin becoming red or in actual burning (Feldman, 1987). Therefore, refugee parents must adjust to socially sanctioned ways of disciplining and healing their children and cope with fear of losing control of their children.

Several postmigration acculturation stressors specific to Southeast Asian refugee children and adolescents have also been identified. Problems may emerge depending upon whether the child is with his or her biological family, adoptive family, or a foster family (Carlin, 1990). Children and adolescents also deal with problems related to their old and new customs as well as living and thinking in two languages (i.e., one for home and one for school). These adjustments may result in identity confusion for refugee children (Carlin, 1990; Hyman, Vu, \& Beiser, 2000). Children may have to serve as interpreters and culture-brokers for adults in their family, thus, totally reversing the roles of authority, power, and respect. A refugee child may be under much pressure to succeed as the hope for the family's future. SEAR youths often encounter conflicts in values between those of their families that have become unfamiliar and those of the mainstream society (Hyman et al., 2000). Thus, SEAR youths may struggle with issues regarding racial identity and ethic identity. Because refugee adolescents tend to feel that their culture is that of their ancestors and not their own, the greatest difficulty in the formation of racial identity in refugee adolescents is not the struggle about belonging to two cultures, but rather the feeling of not belonging to any culture (Tobin \& Friedman, 1984).

The impact of acculturation on education can also be stressful for SEAR youth. School stressors include language and school adjustment, which challenges one's ability to compete successfully in school. For example, children may experience marginalization due to the lack of English fluency as the major source of school stress that creates academic frustration (Hyman et al., 2000). In addition, parents and elders may pressure children to succeed in academics for the entire family or ethnic group (Canino \& Spurlock, 2000). Other stressful experiences include racial discrimination and prejudice. This discrimination has been evidenced in troubled urban public schools and multicultural neighborhoods (Canino \& Spurlock, 2000). Specific to Southeast Asian refugee adolescents, Tobin and Friedman (1984) identified intercultural and developmental stressors. In particular, critical issues of adolescence, such as separation, identity, and sexuality, interacts with critical issues of being a refugee such as loss and grief, survivor guilt, trauma reactions, and cultural discontinuity in adolescent SEAR (Tobin \& Friedman, 1984).

\section{Common mental health problems}

\subsection{Adult clinical presentation}

The most commonly diagnosed mental health problems in Southeast Asian refugee patients are depression, somatization and physical disorders, adjustment disorders, anxiety, and posttraumatic stress disorder (PTSD). In an epidemiological survey in 1983 of 1,684 Vietnamese, Cambodian, and Chinese- Vietnamese refugee residents in Santa Clara County of California, there was an elevated prevalence of depression, anxiety, and impairment of everyday functioning (Meinhardt, 1990). Compared 
with Chinese-Vietnamese (1 $1.7 \%$ ), Vietnamese (1 2.9\%) and the White population of the county (5.6\%), 34\% percent of Cambodians were found to have higher ratings of clinical depression (Meinhardt, 1990). In another study, the Indochinese Psychiatric Clinic in Portland, OR was evaluated during the first 5 years of operation to address the mental health care of 263 SEAR (Kinzie \& Manson, 1983). Primary presenting complaints included somatic symptoms (39\%); disruptive behavior of either a violent or bizarre nature (34\%); and self-reported psychological or interpersonal problems $(27 \%$; Kinzie \& Manson, 1983). The two most prevalent diagnoses in this sample were depression $(n=128$, $49 \%)$ and schizophrenia $(n=49,19 \%)$, and were fairly evenly distributed among the refugee subgroups (i.e., Vietnamese, Cambodian, Laotian, and Hmong; Kinzie \& Manson, 1983). Similarly, Kroll et al. (1989) assessed 404 SEAR (255 Hmong, 71 Laotian, 41 Cambodian, and 37 Vietnamese) residing in Minneapolis, MN. In this sample of SEAR, pain and sleep disturbances were the predominant presenting symptoms, and the most common diagnoses were depression $(n=296,73.3 \%)$ and PTSD $(n=56$, 13.9\%; Kroll et al., 1989). It has also been documented in literature that there is a close relationship between the traumas associated with refugee status and PTSD, related anxiety, and depressive disorders (Marsella, Friedman, \& Spain, 1996).

\subsubsection{Posttraumatic stress disorder}

Due to the nature and extent of refugees' traumatic experiences, research has been conducted to assess the prevalence of PTSD in SEAR. In a mental health needs assessment study, a sample of 2773 SEAR were drawn from nine counties in California (Gong-Guy, 1987). This sample contained 90\% of the SEAR population in California, comprised of 867 Vietnamese, 291 Chinese-Vietnamese, 589 Cambodians, 722 Laotians, and 302 Hmong (Gong-Guy, 1987). According to Gong-Guy (1987), the following percentages of traumatization among Southeast Asian groups were obtained: Cambodians, 43\%; Laotians, 17\%; Hmong, 17\%; and Vietnamese, 14\%. Using the DSM-III-R criteria for PTSD (American Psychiatric Association, 1987), approximately 10\% of this sample met diagnostic criteria with Cambodians experiencing the most PTSD symptoms (16.3\%; Gong-Guy, 1987). One extensive study on PTSD among Indochinese refugees was conducted by Kinzie, Frederickson, Rath, Fleck, and Karls (1984). They surveyed 322 patients at a psychiatric clinic for Indochinese refugees to determine the presence of PTSD. They found that 226 patients (70\%) met the DSM-111-R diagnosis of PTSD. The Mien (Laotian hill people) had the highest rate of PTSD (93\%) whereas the Vietnamese refugees had the lowest (54\%).

\subsection{Gender differences}

There also appears to be a gender difference in adult presentation of mental health problems. Using the same sample of SEAR in the mental health needs assessment (Gong-Guy, 1987), Chung et al. (1998) and Chung, Bemak, and Wong (2002) examined gender differences in psychological presentations. Southeast Asian refugee women reported significantly higher levels of distress than male refugees (Chung \& Bemak, 2002; Chung et al., 1998). Significant predictors of distress (for both men and women) were multiple traumatic events, low English proficiency, low income, no formal education received in home country, and older age (Chung et al., 1998).

\subsubsection{Mental health needs among SEAR subgroups}

Studies have also examined differences in psychological adjustment (e.g., Nicassio, 1983; Rumbaut, 1985) and differential mental health needs (Gong-Guy, 1987) among the SEAR subgroups. Viet- 
namese refugees appear to be better adjusted than other SEAR groups because they have a lower prevalence rate of PTSD, greater happiness, and less depression than Cambodian and Hmong refugees (Rumbaut, 1985), and less alienation than Cambodian, Hmong, and Laotian refugees (Nicassio, 1983). In the aforementioned mental health needs assessment study of 2773 SEAR, needs estimates were derived from five scales assessing physical symptoms, depression, anxiety, difficulty in daily functioning due to emotional or "nervous" problems, and other psychiatric symptoms (Gong-Guy, 1987). The estimates for Cambodian, Lao, and Hmong subgroups were six to seven times more likely to be in severe need (i.e., treatment at intensive outpatient, day treatment, or residential care), and 2.5 to 3 times more likely to experience moderate need (i.e., outpatient services) compared with needs estimates for the general population. Moderate and severe needs estimates for the Vietnamese and Chinese-Vietnamese subgroups were found to be approximately twice the rate of the general population (Gong-Guy, 1987). Overall, these findings indicate that the mental health needs are greater for Cambodian, Hmong, and Laotian refugees than for Vietnamese refugees.

\subsubsection{Limitations of adult research}

In summary, the aforementioned studies provide valuable information regarding adult Southeast Asian refugees' mental health needs. These research studies (e.g., Gong-Guy, 1987; Meinhardt, 1990) are impressive, given the sample size and careful differentiation between subgroups of SEAR. However, data are limited due to research methodology. First, epidemiological surveys provide information about the incidence of psychological problems, but the method in which the data were collected may be problematic. For instance, Meinhardt (1990) described the use of a standardized questionnaire during telephone and direct interviews to obtain information. Problems inherent in this form of survey interviews include response validity and the use of interviewers and/or translators. For example, respondents or translators may respond in some way that is distorted due to their own motivations or self-interest. In addition, studies have retrospectively examined psychiatric assessment data of all Southeast Asian patients who presented at mental health clinics during $\boldsymbol{a}$ specified period of time (e.g., Kinzie \& Manson, 1983; Kroll et al., 1989). Response bias may also be problematic in a clinic setting such that patients may exaggerate their problems to receive treatment.

\subsection{Youth clinical presentation}

\subsubsection{Psychological adjustment of Vietnamese refugee youth}

Several mental health problems have also been identified for Southeast Asian refugee children and adolescents. Chung et al. (2000) employed a sample of 358 Vietnamese college students to examine psychosocial adjustment issues for two different groups of Vietnamese refugees: those who arrived before the war between 1975 and 1977 (i.e., first-wave refugees) and those who arrived after 1978, following the war in their native countries (i.e., second-wave refugees). Second-wave Vietnamese students reported more psychological distress than the first wave. In addition to the differences in the traumas these two groups experienced, they were also significantly different in the age when they arrived in the United States. First-wave refugee respondents arrived when they were approximately 3 years old, whereas second-wave refugees were approximately 11 years old (Chung et al., 2000). The authors suggest that acculturation at an early developmental stage may have protected the first-wave Vietnamese youth from experiencing psychosocial adjustment difficulties. This study is impressive due to the large sample size and ability to differentiate the two waves of Vietnamese refugees. On one hand, the use of a college sample accesses high-functioning Vietnamese refugees and provides some informa- 
tion about adaptive functioning following migration to a new country. By the same token, however, the use of a college sample limits the generalizability of these results to other refugee populations.

\subsubsection{Posttraumatic stress and depressive disorders among Cambodian refugee youth}

A series of studies were conducted longitudinally to examine the effects of war trauma on Cambodian youths. In 1984, 46 Cambodian high school students (average age of 17) were interviewed (Kinzie, Sack, Angell, Manson, \& Rath, 1986). Six of these forty-six refugees escaped the Pol Pot regime. From the remaining 40 students who were affected by the Pol Pot experience, the majority of these refugees were forced into labor camps $(n=39)$, where they resided in age-segregated camps $(n=36)$. Respondents reported the following traumatic experiences: $83 \%$ were separated from their family $(n=33$ ); $80 \%$ lost at least one family member through death or missing ( $n=32) ; 61 \%$ witnessed killings of others $(n=17)$ or family members $(n=7) ; 38 \%$ of the participants or their family members were beaten $(n=15) ; 83 \%$ suffered malnutrition $(n=33)$; and 50\% felt that their life was endangered while residing in Thailand (Kinzie et al., 1986). Fifty percent of the sample met the full diagnostic criteria for current PTSD (based on the DSM-III-R), whereas 53\% met diagnostic criteria for depression (Kinzie et al., 1986). Furthermore, 17 of the 20 Cambodian students with PTSD also had a depressive disorder (Kinzie et al., 1986). Follow-up interviews were conducted after 3 years with 27 of the original 40 participants who had experienced the Pol Pot regime and revealed that 48\% had PTSD and 4 1\% had a depressive disorder based on the DSM-III-R (Kinzie, Sack, Angell, Clarke, \& Ben, 1989). A 6year follow-up with 29 of the 40 original Cambodian students who had endured the Pol Pot showed that 38\% were diagnosed with PTSD, whereas depression dropped to 6\% (Sack et al., 1993). One additional study was conducted as a 12-year follow-up with 27 participants from the original study and revealed that PTSD diagnoses continued to decline (35\%) whereas depression diagnoses increased slightly (14\%; Sack, Him, \& Dickason, 1999). Conduct disorders were not identified throughout any of these longitudinal studies and, although participants met criteria for PTSD and depressive disorders diagnoses, overall, they were found to be functioning well (Kinzie et al., 1986, 1989; Sack et al., 1993). It is also important to note that the PTSD diagnosis did not necessarily affect the same participants (i.e., some cases resolved over time and a few new cases arose between the first and second study; Kinzie et al., 1998). Although PTSD and depression were initially believed to be comorbid conditions, separate clinical courses were revealed in this sample. That is, depression greatly decreased over time while PTSD remitted only slightly (Sack et al., 1993, 1999). Given the sparse amount of longitudinal research on refugee youth, these studies are of great value in helping to understand the trajectory of refugee youth's mental health. Unfortunately, due to the small sample size and lack of replication with other samples, these findings may not be representative of all SEAR youth, or even representative of all Cambodian youths who survived the Pol Pot regime.

The rates of PTSD and depression in two generations of Cambodian refugees were also examined as part of an epidemiological study of Cambodian refugees. The sample consisted of 209 Cambodian adolescents (ages 13 to 25) and 180 of their parents from two western U.S. communities (Sack et al., 1994). There was a relationship between adolescents' and parents' PTSD diagnoses such that there was a trend for higher PTSD rates among adolescents when both parents were diagnosed with PTSD (Sack et al., 1994). Specifically, when neither parent had PTSD, only $12.9 \%$ of youth received the diagnosis. However, when one parent had PTSD, the adolescent prevalence rate increased to $23.3 \%$. Lastly, when both parents were diagnosed, the rate increased to 41.2\% (Sack et al., 1994). These results suggest that when one parent is exposed to trauma, the youth is also more likely to have endured some form of traumatic event and experienced subsequent posttraumatic stress symptoms. 
In another set of studies conducted with Cambodian adolescents and young adults, the relationship between three forms of stress (war trauma, resettlement strain, and recent life events) and PTSD and depression were assessed (Clarke, Sack, \& Goff, 1993; Sack, Clarke, \& Seeley, 1996). Clarke et al. (1993) interviewed 69 Cambodian adolescents and young adults. They found that for individuals with PTSD, war trauma significantly accounted for $15.4 \%$ of symptom variance, and resettlement stress accounted for an additional $11.7 \%$ of variance (Clarke et al., 1993). For persons with Major Depressive Disorder, the significant predictors included recent life stressors $(8.3 \%)$, war trauma stressors $(6.7 \%)$, and inferior English language skill rating (5.1\%; Clarke et al., 1993). Similar findings were reported by Sack et al. (1996) in their sample of 170 Cambodian youth and 80 of their mothers who were interviewed regarding DSM-III- $R$ diagnoses of PTSD and depressive disorders, and the stress of war trauma, resettlement, and recent life events. A consistent relationship was found between earlier war trauma (11.1\% of variance), resettlement stress (first-year stress accounted for $6.1 \%$ ), and symptoms of PTSD (Sack et al., 1996). In contrast, the strongest relation with depressive symptoms was found for recent stressful events and lower English language ability ratings, accounting for $7.4 \%$ and $4.5 \%$ of the variance, respectively (Sack et al., 1996). Therefore, war trauma was strongly related to and predictive of PTSD, but not depressive disorders. Additionally, these findings suggest that symptoms of depression, in contrast to symptoms of PTSD, are less enduring and appear to relate to recent stressors. Finally, these studies show that children who survive a war and have endured traumatic experience continue to carry specific symptoms of that experience through subsequent development and into the beginning of their adult lives (Clarke et al., 1993; Sack et al., 1996).

\subsubsection{Limitations of youth research}

Although several studies indicate that PTSD and depressive disorders are prevalent among Cambodian youths (Clarke et al., 1993; Kinzie et al., 1986, 1989; Sack et al., 1993, 1996, 1999, 1994), caution is warranted in generalizing the results to other samples of refugee youth (e.g., Hmong and Laos). Additionally, the retrospective nature of the data collection in the aforementioned studies carries risks. As with all retrospective research, participants may provide inaccurate or distorted information regarding stressful events occurring during childhood. Unfortunately, the literature base is not sufficient to document the presence of mental disorders among SEAR youth. Instead, it is necessary to consider premigration stressors, such as traumatic experiences (e.g., Kinzie et al., 1986), and contextual factors, such as resettlement and current stressors (e.g., Sack et al., 1996), when addressing mental health problems in youth SEAR. These stressors appear to have a direct impact on the manifestation of an individual's clinical presentation.

\section{Resilience and protective variables}

SEAR have experienced both premigration and postmigration acculturation stressors that challenge their traditional cultural values. These stressors have been identified as variables that place SEAR at risk for developing psychological symptoms and disorders. Despite the experiences SEAR have endured, such as persecution, flight, and resettlement, most refugees do not present for mental health services. It is possible that the stigma and shame attached with mental illness prevent Asian clients from seeking psychological services (e.g., $\mathrm{Ng}, 1997)$. It is also likely that resilience and protective vari- 
ables serve as buffers against developing mental health problems. The stress process model "posits that stress exerts a direct effect in producing psychological distress and disorder, it also suggests that social and personal resources, often neglected in refugee research, may directly affect mental health, or, by altering the experience of stress, may buffer a person against its effects" (Beiser, 1990, pp. 5556). In addition to social and personal resources, familial resources and individual coping strategies have been identified as protective factors for SEAR in adjusting to a new country (Beiser et al., 1989).

Individual coping strategies include factors such as language proficiency and focusing on the present and the future while avoiding the past. For example, in one study comparing first-and second-wave Vietnamese youth refugees, age of arrival to the U.S. was identified as an important protective factor (Chung et al., 2000). Specifically, youths who arrived in early childhood (i.e., mean age of 3 years) were found to have better psychosocial adjustment than youths who arrived during late childhood (i.e., mean age of 11 years). Authors suggest this difference occurred because the children began their acculturation process at an earlier developmental level when language and culture were more easily formed (Chung et al., 2000). Language proficiency has also been demonstrated to serve as a buffer against development of depressive symptoms (Clarke et al., 1993; Sack et al., 1996).

Another personal resource is related to time perspective. Beiser (1987) examined the changing time perspective and mental health among SEAR using case studies of SEAR $(n=1169)$ and residents of Vancouver $(n=319)$. Results suggest that altering one's perception of time may be an adaptive strategy. During periods of acute stress, refugees appear to focus on the present while splitting off the past and future as a survival strategy (Beiser, 1987). Under these difficult circumstances, splitting off time spheres and not allowing the past to obtrude into consciousness may be one way to protect their mental health (Beiser, 1987). According to Beiser, a "nostalgic" time orientation (i.e., preoccupation with the past) is associated with elevated depression scores. Therefore, the reemergence of past and future into consciousness brings about a risk for developing depression. During the early years of resettlement, the ability to split time seems to characterize a large segment of the refugee population and serve as evidence that it may operate to ward off depression (Beiser, 1987). The most common choices of time perspective for SEAR were on the future perspective, where the focus was on optimism and hope (Beiser, 1987). Therefore, it is important for SEAR to focus on the present and the future during the early years of resettlement (Beiser \& Hyman, 1997).

Family resources and relationships also affected mental health risk in SEAR. When SEAR were separated from their spouses, it had the greatest psychological impact in contrast to separation from parents and siblings (Beiser \& Hyman, 1997). Marital status appeared to be an important protective factor such that married refugees whose spouses were with them in Canada had lower levels of depression than single, divorced, or widowed adults or those involuntarily separated by circumstances (Beiser, Johnson, \& Turner, 1993). In addition, single refugees who married also experienced an improvement in mental health whereas people who separated, divorced, or were widowed experienced a decline in mental health (Beiser et al., 1993). Furthermore, refugees who were eventually able to bring their relatives to Canada experienced an improvement in mental health (Beiser et al., 1993).

Social support from ethnic communities also served as a protective factor in adjusting to a new country for SEAR (Beiser et al., 1989). Social resources were provided to SEAR in the form of government or private sponsorship in Canada (Beiser \& Hyman, 1997). SEAR received income support for 1 year or until the refugee became self-sufficient. It was hypothesized that refugees who received private sponsorship would experience better mental health than those who were government sponsored due to more attention given by individuals to refugees. However, data based on a community survey 
of 1348 SEAR contradicted this prediction (Beiser et a]., 1989). Several possible explanations were offered: (a) private sponsors tended to find housing for refugees that at the termination of the sponsorship, SEAR could no longer afford; (b) housing was found to be accessible to the private sponsors rather than in areas the refugees might have preferred (i.e., close to ethnic communities or to potential workplaces); and (c) private sponsors were overly intrusive or indifferent (Beiser et al., 1989). Chung et al. (1 998) emphasize that social support from one's own ethnic or alike-ethnic communities is important because it enhances a sense of identity and belonging. Therefore, social support has a beneficial effect on mental health and can also act as a buffer to stressful events (Chung et al., 1998).

\section{Clinical implications}

\subsection{Assessment issues}

Given the stigma that may be associated with seeking mental health services, it is very important to build up a therapeutic relationship. During the assessment phase, the mental health provider should not be in a hurry. Clinicians should be aware of nonverbal communication and pay attention to the physical symptoms the client describes, as the physical symptoms may be easier for the client to discuss. After the client feels that the clinician has an understanding of these symptoms, then the clinician can more easily inquire about psychological stressors and symptoms (Ying, 1997). Given the close relationship between the traumas associated with refugee status and PTSD, related anxiety, and depressive disorders (Marsella et al., 1996), it is important to assess for these psychological problems as well as comorbidity of these disorders.

To avoid misdiagnosis and improper treatment, the mental health provider must remember that mainstream methods of diagnosis and testing may not be applicable to SEAR patients. Language discrepancies between the patient and clinician can lead to miscommunication and increase the chances of misdiagnosis or improper treatment. When a language barrier exists between the clinician and patient, the use of interpreters should be conducted with caution and careful training to reduce the chance of misinterpretation and potential interpreter biases (Lee, 1997). In addition to language barriers between clinician and patient, conceptual differences between Asian and Western cultures in the expression of mental illness must be considered. For example, Chung and Kagawa-Singer (1995) found that SEAR typically express psychological distress in patterns consistent with Asian nosology rather than the patterns described in Western culture. Thus, Asian culture often describes depression as problems with eating, sleeping, feeling tired, irritable, and having headaches, backaches, or digestive problems, whereas Western culture describes depression as feeling sad or down. Given the different cultural expressions of psychological problems, clinicians should use assessment tools that are not only reliable, but are also conceptually valid for SEAR patients. Although the use of culturally validated measures is extremely important, very few culturally validated measures for use with SEAR exist. A few culturally validated scales, however, have been developed. For example, the Hopkins Symptom Checklist, a scale used to measure symptoms of depression and anxiety, has been culturally validated by Mollica, Wyshak, Marneffe, Khuon, and Lavelle (1987). Additionally, the Harvard Trauma Questionnaire has been culturally validated as appropriate for evaluation of PTSD symptoms in Cambodian, Laotian, and Vietnamese refugees (Mollica et al., 1992). 
Consistent with any clinical assessment, it is important to obtain a thorough social history in addition to the psychiatric symptoms. When working with SEAR clients, however, specific issues should be assessed. The clinician should gather information about premigration stressors and traumas, refugee camp experience, separation from and loss of significant others, postmigration stressors, cultural identity and acculturation, and availability of social support (Du \& Lu, 1997). To aid clinicians in gathering culturally relevant information, Tanaka-Matsumi, Seiden, and Lam (1996) have developed the Culturally Informed Functional Assessment Interview. By attending to these cultural factors, clinicians are able to generate culturally sensitive treatment options, and thus increase treatment effectiveness.

\subsection{Treatment of mental health problems}

Several factors have major implications for treatment of Southeast Asian patients seeking mental health services. First, the basic needs (e.g., assistance with food, clothing, finances, vocation) of these patients should not be ignored. It is important to offer help in obtaining social and financial assistance that can reduce current stress in the patient's life (Kinzie, 1989). Because of the stigma attached to mental illness, many SEAR do not present to mental health professionals for treatment. In fact, many come into contact with a mental health provider only after presenting to a general practitioner with multiple somatic complaints that cannot be accounted for by an organic cause. Because many SEAR are not familiar with psychological services, it is important to spend time educating SEAR patients about the delivery of mental health services.

Based on extensive clinical work with traumatized SEAR clients, Kinzie (1989) found limited utility in brief, time-limited psychotherapy approaches. Additionally, no treatment outcome studies utilizing behavioral or cognitive therapies with traumatized SEAR have been conducted (Du \& Lu, 1997). Although very few treatment efficacy studies with SEAR patients exist, several treatment recommendations can be drawn from the literature. Based on his clinical experience with SEAR patients, Kinzie (1989) recommends using a long-term supportive therapy approach when treating SEAR. Ideally, the course of treatment in working with traumatized SEAR would consist of building a strong therapeutic alliance and beginning individual therapy using supportive techniques and taking into consideration cultural factors (Du \& Lu, 1997; Kinzie, 1989). It is worthwhile to reinforce the cultural values of SEAR during clinical interventions. For instance, SEAR may continue to use traditional healing methods (e.g., indigenous healers, folk medicine; Chung \& Lin, 1994). This can be viewed as complementary to psychological services rather than as an opposing method of treatment. Additionally, it is crucial to consider religious belief systems. Several Buddhist concepts can be applied in treatment and can serve as protective factors for the client. Kinzie (1989) states that ancestral worshiping can help the patient maintain contact with the past and provide a sense of continuity of life; the concept of karma may often help diffuse a personal sense of survivor guilt or shame, and Buddhist prohibition against suicide can be a "powerful ally" when working with a suicidal patient.

Since research has shown that refugees who report more psychosocial problems also report greater dissatisfaction with their social support networks (Chung et al., 2000), the next phase in the course of treatment of traumatized SEAR is to increase family and community involvement and socialize the client to group therapy (Du \& Lu, 1997; Kinzie, 1989). Due to the emphasis on familial roles and respect for the SEAR, family-centered therapy may be beneficial. Based on the research literature pertaining to protective variables, it would be important to access family resources and facilitate the pa- 
tient's awareness of community support programs. Chung et al. (2000) have recommended that clinical interventions involving social support networks focus on (a) existing families and social networks that are dysfunctional, (b) providing support and reinforcement for already established healthy social networks, and (c) facilitating the formation of social networks when there is an absence of family or friends. These recommendations may be accomplished by establishing and encouraging attendance in group therapy, extended family counseling, or other group experiences. Getting SEAR to engage in group therapy experiences, however, may be difficult because they have little cultural experience with self-disclosure. Some researchers have found that refugees enjoy group therapy that emphasizes group activities and socialization activities that help clients learn about everyday activities in the United States such as how to shop, rent, obtain insurance, get a drivers license (Kinzie, Leung, \& Boehnlein, 1997). This type of group therapy can supplement individual therapy.

Another adjunct to psychological treatment for some SEAR clients may be pharmacological treatment. Although many Asian clients seeking treatment will expect medication to be part of the treatment, several cultural issues should be considered when utilizing psychotropic medications with SEAR. For example, one difficulty in treatment with medication is noncompliance (e.g., Kinzie, Leung, Boehnlein, \& Fleck, 1987; Kroll et al., 1990). Noncompliance frequently occurs because Asian clients are not willing to tolerate additional somatic side effects of many psychotropic medications. Supporting this notion is evidence that suggests that Asians require a lower dosage of psychotropic drugs to achieve therapeutic effects and limit side effects (e.g., Bond, 1991). Other cultural factors to consider when using pharmacological treatment is that traditionally oriented Asians may expect the medication to relieve symptoms in a short period of time and may expect medication to relieve all symptoms. Then, they may stop the medication once they feel better. Thus, education about the use of psychotropic medication is an important step in the utilization pharmacological interventions ( $\mathrm{Du} \& \mathrm{Lu}, 1997$ ).

As mental health professionals, it is important to have specific knowledge about SEAR, and this knowledge should include how historical factors vary among Southeast Asian refugee subgroups. Kinzie (1989) describes several problems that may be present for therapists when working with SEAR, such as being insensitive to the patient's culture and his/her expectations, being culturally ignorant, and experiencing countertransference feelings, which may prevent direct questioning or listening to traumatic stories. Because studies have found subtle but important differences between SEAR subgroups (e.g., Chung \& Bemak, 2002), it is critical to treat each patient individually and address the complexities of each case within the working knowledge about SEAR. When providing psychological treatment, SEAR should not be clustered together or assumed to react to the stressors in the same manner. In fact, clinical interventions should be designed to the unique needs of the SEAR client and, thus, increasing the likelihood that mental health services will be effective for the individual.

\section{Future directions in research}

Currently, there is a limited amount of literature examining the mental health needs of SEAR. In addition, this literature base is somewhat restricted as most of the empirical research used large data sets from epidemiological studies conducted in the 1980s. Furthermore, the literature that focuses on the implications of cultural values on mental health needs is primarily based on clinical impressions and speculations rather than empirical data. It should be understood that although studies are lacking and the data may seem dated, the results of these data are still applicable to today's refugee population and their mental health given that resettlement policies and services have not changed much in the last sev- 
eral decades (Chung \& Bemak, 2002). However, given the limitations of the literature, additional empirical research investigating the mental health needs of SEAR is warranted in several areas.

First, much of the research to date has focused on the premigration trauma suffered by SEAR and has neglected to examine postmigration factors (e.g., employment, income, English proficiency), which may also influence refugees' mental health. The limited research that is available suggests that these postmigration factors play a meaningful role in the mental health of refugees (Chung \& Bemak, 2002). Thus, future research needs to examine the complex multidimensional (e.g., premigration, postmigration factors) interaction of the experiences endured by SEAR to better address the mental health needs of refugees.

Second, although the empirical literature on Southeast Asian refugee adults has carefully differentiated among the Southeast Asian refugee subgroups (e.g., Gong-Guy, 1987; Meinhardt, 1990), the research literature on SEAR youth has primarily focused on Vietnamese and Cambodian youth. Thus, an important area to examine in future research is the long-term adjustment of Hmong or Laotian youth. Additionally, future studies should continue to explore intergroup ethnic differences, as well as gender and age differences among Southeast Asian refugee subgroups due to their unique experiences. Conducting longitudinal research that includes in-depth examination of age, gender, and ethnic differences will allow researchers to gain insight about how the psychosocial adjustment of SEAR may change over time, as well as increase our understanding about the complex interaction between ethnicity, gender, and age in the SEAR population. Moreover, future research should examine the impact of the unique historical factors that may influence the psychological functioning of the various SEAR subgroups. For example, one question that has not been addressed in the literature is how the United States' involvement in the Vietnam War influences refugees' mental health and subsequent treatment.

Another area in which there is a significant lack of empirical data regarding SEAR is in the assessment and treatment domain. As described earlier, Asians typically express psychological problems differently than those from Western cultures; therefore, there is a need for culturally sensitive assessment tools to be developed and validated for use with SEAR clients. Future studies should strengthen the cultural validity of diagnostic assessments by utilizing confirmatory models of factor analysis, ethnographic interviews, and comparison groups (Chung \& Kagawa-Singer, 1995). Additionally, more treatment outcome research with SEAR samples is greatly needed. No empirical data regarding the efficacy of behavior therapy or cognitive therapy with traumatized SEAR clients exist (Du \& Lu, 1997). Although treatment recommendations have been offered by several authors (e.g., Kinzie, 1989), these recommendations are frequently based on anecdotal evidence and clinical experience rather than objective, empirical data. Finally, additional research on protective factors (e.g., adaptive coping strategies, social support) that result in well-adjusted, resilient SEAR is required. This examination of SEAR'S strengths and resiliency has direct implications for the development of prevention and intervention programs for future refugees.

\section{Conclusion}

As refugees leave their native countries and migrate to a new country, mental health professionals attempt to provide assistance during this period of resettlement. This article provides an overview and review of the literature on one group of refugees, SEAR, in an attempt to elucidate the historical, cultural, and contextual challenges that affect the mental health needs of SEAR during the readjustment period. When examining historical, cultural, and contextual factors, the need for psychological servic- 
es does exist for many SEAR. However, one problem that emerges is that most SEAR do not present for mental health services. Therefore, it is important to examine the cultural views on mental illness and develop treatment interventions that would be consistent with traditional values. In addition, specific resilience and protective factors appear to serve as a buffer to manifestations of psychiatric disorders. Therefore, historical, cultural, and protective factors need to be further examined by researchers and clinicians to better understand the mental health needs of SEAR.

The conceptualization provided in this review is intended to serve as a guideline to assist in understanding one refugee population. As evidenced in this article, refugees from Southeast Asia present with similar experiences due to war-induced trauma and stressors related to migration and readjustment to a foreign country. Despite these similarities, differences are evident among the SEAR and, thus, the subgroups of SEAR were examined. It is important to explore possible differences within one group of refugees as subgroups are apparent and should be considered uniquely. It is also important to examine individual differences within each subgroup given that each person has distinct experiences and are affected by them in different ways. Additionally, it is imperative to establish that mental health needs do exist for future refugees by exploring historical and contextual challenges. Furthermore, cultural factors must be considered as these values have direct implications on how an individual perceives traumatic experiences and the adaptation process. Lastly, protective factors need to be examined. This method of conceptualizing Southeast Asian refugees' experiences can be applied to future refugees.

\section{References}

Abueg, F. R., \& Chun, K. M. (1996). Traumatization stress among Asian and Asian Americans. In A. J. Marsella, M. J. Friedman, E. T. Gerrity, \& R. M. Scurfield (Eds.), Ethnocultural aspects of posttraumatic stress disorder: Issues, research, and clinical applications (pp. 285-299). Washington, DC: American Psychological Association.

American Psychiatric Association (1987). Diagnostic and statistical manual of mental disorders (3rd, revised). Washington, DC: Author,

Beiser, M. (1987). Changing time perspective and mental health among Southeast Asian refugee. Culture, Medicine and Psychiatry, 11, 437-464.

Beiser, M. (1 990). Mental health of refugees in resettlement countries. In W. H. Holtzman, \& T. H. Bornemann (Eds.), Mental health of immigrants and refugees (pp. 51-65). Austin, TX: Hogg Foundation for Mental Health, The University of Texas.

Beiser, M., \& Hyman, I. (1997). Southeast Asian refugees in Canada. In I. Al-Issa, \& M. Tousignant (Eds.), Ethnicity, immigration, and psychopathology (pp. 35-56). New York: Plenum.

Beiser, M., Johnson, P. J., \& Turner, R. J. (1993). Unemployment, underemployment and depressive affect among Southeast Asian refugees. Psychological Medicine, 23, 731-743.

Beiser, M., Turner, R. J., \& Ganesan, S. (1989). Catastrophic stress and factors affecting its consequences among Southeast Asian refugees. Social Science Medicine, 27, 183-195.

Bhugra, D., \& Cordle, C. (1988). A case control study of sexual dysfunction in Asian and non-Asian couples 19811985. Sexual and Marital Therapy, 3, 71-76.

Boehnlein, J. K. (1987). Culture and society in posttraumatic stress disorder: Implications for psychotherapy. American Journal of Psychotherapy, 41, 519-530.

Boehnlein, J. K., \& Kinzie, J. D. (1997). Cultural perspectives on posttraumatic stress disorder. In T. W. Miller (Ed.), Clinical disorders and stressful life events. International Universities Press Stress And Health Series. Monograph, vol. 7 (pp. 19-43). Madison, CT: International Universities Press. 
Bond, W. S. (1991). Therapy update: Ethnicity and psychotropic drugs. Clinical Pharmacology, 10, 467-470.

Canino, I. A., \& Spurlock, J. (2000). Culturally diverse children and adolescents: Assessment, diagnosis, and treatment (2nd ed.). New York: Guilford Press.

Carlin, J. E. (1990). Refugee and immigrant populations at special risks: Women, children, and the elderly. In W. H. Holtzman, \& T. H, Bornemann (Eds.), Mental health of immigrants and refugees (pp. 224-244). Austin, TX: Hogg Foundation for Mental Health.

Chan, S., \& Leong, C. W. (1 994). Chinese families in transition: Cultural conflicts and adjustment problems. Journal of Social Distress and the Homeless, 3, 263-281.

Chung, R. C., \& Bemak, F. (2002). Revisiting the California Southeast Asian mental health needs assessment data: An examination of refugee ethnic and gender differences. Journal of Counseling and Development, 80, 111-119.

Chung, R. C., Bemak, F., \& Kagawa-Singer, M. (1998). Gender differences in psychological distress among Southeast Asian refugees. Journal of Nervous and Mental Disease, 186, 112-119.

Chung, R. C., Bemak, F., \& Wong, S. (2000). Vietnamese refugees' level of distress, social support, and acculturation: Implications for mental health counseling. Journal of Mental Health \& Counseling, 22, 150-161.

Chung, R. C., \& Kagawa-Singer, M. (1995). Interpretation of symptom presentation and distress: A Southeast Asian refugee example. Journal of Nervous and Mental Disease, 183, 639-648.

Chung, R. C., \& Lin, K. (1994). Help-seeking behavior among Southeast Asian refugees. Journal of Community Psychology, 22, 109-120.

Clarke, G., Sack, W. H., \& Goff, B. (1993). Three forms of stress in Cambodian adolescent refugees. Journal of Abnormal Child Psychology, 21, 65-77.

de Silva, P. (1999). Cultural aspects of post-traumatic stress disorder. In W. Yule (Ed.), Post-traumatic stress disorder (pp. 116-138). New York: Wiley.

Du, N., \& Lu, F. G. (1997). Assessment and treatment of posttraumatic stress disorder among Asian Americans. In E. Lee (Ed.), Working with Asian Americans: A guide for clinicians (pp. 275-294). New York: Guilford Press.

Feldman, K. W. (1987). Child abuse by burning. In R. E. Helfer, \& R. S. Kempe (Eds.), The battered child (4th ed.) (pp. 197-213). Chicago: University of Chicago Press.

Flaskerud, J. H., \& Anh, N. T. (1988). Mental health need of Vietnamese refugees. Hospital and Community Psychiatry, 39, 435-437.

Futa, K. T., Hsu, E., \& Hansen, D. J. (2001). Child sexual abuse in Asian American families: An examination of cultural factors that influence prevalence, identification, and treatment. Clinical Psychology: Science and Practice, 8, 189-209.

Gong-Guy, E. (1987). The California Southeast Asian mental health needs assessment. Sacramento, CA: California State Department of Mental Health (Contract No. 85-76282A-2).

Ho, C. K. (1990). An analysis of domestic violence in Asian American communities: Multicultural approach to counseling. Women and Therapy, 9, 129- 150.

Hyman, I., Vu, N., \& Beiser, M. (2000). Post-migration stresses among Southeast Asian refugee youth in Canada: A research note. Journal of Comparative Family Studies, 31, 281 -293.

Ito, K. L., Chung, R. C., \& Kagawa-Singer, M. (1997). Asian/Pacific American women and cultural diversity: Studies of the traumas of cancer and war. In S. B. Ruzek, V. L. Olesen, \& A. Clarke (Eds.), Women's health: Complexities and differences (pp. 300-328). Columbus, OH: Ohio State University Press.

Kessner, T., \& Caroli, B.B. (1982). Today's immigrants, their stories: A new look at the newest Americans. New York: Oxford University Press.

Kinzie, J. D. (1989). Therapeutic approaches to traumatized Cambodian refugees. Journal of Traumatic Stress, 2, $75-91$.

Kinzie, J. D., Boehnlein, J., \& Sack, W. I-I. (1998). The effects of massive trauma on Cambodian parents and children. In Y. Danieli (Ed.), International handbook of multigenerational legacies of trauma (pp. 211-221). New York: Plenum. 
Kinzie, J. D., Frederickson, R., Rath, B., Fleck, J., \& Karls, W. (1981). Post-traumatic stress disorder among survivors of Cambodian concentration camps. American Journal of Psychiatry, 141, 645-650.

Kinzie, J. D., Leung, P. K., \& Boehnlein, J. K. (1997). Treatment of depressive disorders in refugees. In E. Lee (Ed.), Working with Asian Americans: A guide for clinicians (pp. 265-274). New York: Guilford Press.

Kinzie, J. D., Leung, P., Boehnlein, J. K., \& Fleck, J. (1987). Antidepressant blood levels in South Asians. Journal of Nervous and Mental Disease, 175, 480-485.

Kinzie, J. D., \& Manson, S. (1983). Five-years' experience with Indochinese refugee psychiatric patients. Journal of Operational Psychiatry, 14, 105-111.

Kinzie, J. D., Sack, W. H., Angell, R. H., Clarke, G., \& Ben, R. (1989). A three-year follow-up of Cambodian young people traumatized as children. Journal of the American Academy of Child and Adolescent Psychiatry, 28, 501504.

Kinzie, J. D., Sack, W. H., Angell, R. N. Manson, S., \& Rath, B. (1986). The psychiatric effects of massive trauma on Cambodian children: I. The children. Journal of the American Academy of Child and Adolescent Psychiatry, 25, 370-376.

Kroll, J., Habenicht, M., Mackenzie, T., Yang, M., Chan, S., Vang, T., Nguyen, T., Ly, M., Phommasouvanh, B., Nguyen, H., Vang, Y., Souvannasoth, L., \& Cabugao, R. (1989). Depression and posttraumatic stress disorder in Southeast Asian refugees. American Journal of Psychiatry, 146, 1592-1597.

Kroll, J., Linde, P., Habenicht, M., Chan, S., Yang, M., Vang, T., Souvannasoth, L., Nguyen, T., Ly, M., Nguyen, H., \& Vang, Y. (1990). Medication compliance, antidepressant blood levels and side effects in Southeast Asian patients. Journal of Clinical Psychopharmacology, 10, 279-283.

Kunz, E. F. (1973). The refugee in flight: Kinetic models and forms of adjustment. International Migration Review, 7, 126-146.

Lee, E. (1996). Asian American families: An overview. In M. McGoldrick, J. Giordano, \& J. K. Pearce (Eds.), Ethnicity and family therapy (2nd ed.) pp. 227-248). New York: Guilford Press.

Lee, E. (1997). Cross-cultural communication: Therapeutic use of interpreters. In E. Lee (Ed.), Working with Asian Americans: A guide for clinicians (pp. 477-489). New York: Guilford Press. Lee, E., \& Lu, F. (1989). Assessment and treatment of Asian-American survivors of mass violence. Journal of Traumatic Stress, 2, 93-120.

Marsella, A. J., Friedman, M. J., \& Spain, E. H. (1996). Ethnocultural aspects of PTSD: An overview of issues and research directions. In A. J. Marsella, M. J. Friedman, E. T. Gerrity, \& R. M. Scurfield (Eds.), Ethnocultural aspects of posttraumatic stress disorder: Issues, research, and clinical applications (pp. 105-129). Washington, DC: American Psychological Association.

Mattson, S. (1993). Mental health of Southeast Asian refugee women: An overview. Health Care for Women International, 14, 155-165.

Meinhardt, K. (1990). Contribution of epidemiological surveys to planning and evaluating clinical services. In W. H. Holtzman, \& W. H. Bornemann (Eds.), Mental health of immigrants and refugees (pp. 185-189). Austin, TX: Hogg Foundation for Mental Health.

Mollica, R. (1994). Southeast Asian refugees: Migration history and mental health issues. In A. J. Marsella, T. Bornemann, S. Ekblad, \& J. Orley (Eds.), Amidst peril and pain: The mental health and well-being of the world's refugees (pp. 83-100). Washington, DC: American Psychological Association.

Mollica, R. F., \& Caspi-Yavin, Y. (1992). Overview: The assessment and diagnosis of torture events and symptoms. In M. Basoglu (Ed.), Torture and its consequences: Current treatment approaches (pp. 253-274). Cambridge, UK: Cambridge University Press.

Mollica, R. F., Caspi-Yavin, Y., Bollini, P., Truong, T., Tor, S., \& Lavelle, J. (1992). Validity of Harvard Trauma Questionnaire. Journal of Nervous and Mental Disease, 180, 111-1 16.

Mollica, R. F., Wyshak, G., Marneffe, D., Khuon, F., \& Lavelle, J. (1987). Indochinese version of the Hopkins Symptom Checklist-25: A screening instrument for the psychiatric care of refugees. American Journal of Psychiatry, 144, 497-500. 
Morrow, R. D. (I 994). Immigration, refugee and generation status as related to behavioral disorders. In R. L. Peterson, \& S. Ishii-Jordan (Eds.), Multicultural issues in the education of students with behavioral disorders (pp. 196-207). Cambridge, MA: Brookline Books.

Nicassio, P. M. (1983). Psychosocial correlates of alienation. Journal of Cross-Cultural Psychology, 14, 337-35 1. Ng, C. H. (1997). The stigma of mental illness in Asian cultures. Australian and New Zealand Journal of Psychiatry, 31, 382-390.

Office of Refugee Resettlement (1990, February). Update. Washington, DC: U.S. Department of Health and Human Services.

Pernice, R., \& Brook, J. (1994). Relationship of migrant status (refugee or immigrant) to mental health. International Journal of Social Psychiatry, 40, 177-188.

Rumbaut, R (1985). Mental health and the refugee experience: A comparative study of Southeast Asian refugee. In T. C. Owan (Ed.), Southeast Asian mental health: Treatment, prevention, services, training, and research (pp. $433-$ 486). Rockville, MD: National Institute of Mental Health.

Sack, W. H., Clarke, G., Him, C., Dickason, D., Goff B., Lanham, K., \& Kinzie, J. D. (1993). A six-year follow-up of Cambodian youth traumatized as children. Journal of the American Academy of Child and Adolescent Psychiatry, 32, $431-437$.

Sack, W. H., Clarke, G. N., \& Seeley, J. (1996). Multiple forms of stress in Cambodian adolescent refugees. Child Development, 67, 107-1 16.

Sack, W. H., Him, C., \& Dickason, D. (1999). Twelve-year follow-up study of Khmer youths who suffered massive war trauma as children. Journal of the American Academy of Child and Adolescent Psychiatry, 38, 1173-1179.

Sack, W. H., McSharry, S., Clarke, G. N., Kinney, R., Seeley, J., \& Lewinsohn, P. (1994). The Khmer adolescent project: I. Epidemiological findings in two generations of Cambodian refugees. Journal of Nervous and Mental Disease, 182, 387-395.

Sandhu, D. S. (1997). Psychocultural profiles of Asian and Pacific Islander Americans: Implications for counseling and psychotherapy. Journal of Multicultural Counseling and Development, 25, 7-22. Shon, S. P., \& Ja, D. Y. (1982). Asian families. In M. McGoldrick, J. Pearce, \& J. Giordano (Eds.), Ethnicity and family therapy (pp. 208229). New York: Guilford Press.

Strober, S. B. (1994). Social work intervention to alleviate Cambodian refugee psychological distress. International Social Work, 37, 23-35.

Tanaka-Matsumi, J., Seiden, D. Y., \& Lam, K. N. (1996). The Culturally Informed Functional Assessment (CIFA) interview: A strategy for cross-cultural behavioral practice. Cognitive and Behavioral Practice, 3, 2 15-233.

Tobin, J. J., \& Friedman, J. (1984). Intercultural and developmental stresses confronting Southeast Asian refugee adolescents. Journal of Operational Psychiatry, 15, 39-45.

Tran, C. G., \& Des Jardins, K. (2000). Domestic violence in Vietnamese refugee and Korean immigrant communities. In J. L. Chin (Ed.), Relationships among Asian American women (pp. 71-100). Washington, DC: American Psychological Association.

Uba, L. (1994). Asian Americans: Personality patterns, identity, and mental health. New York: Guilford Press. Vu, T.Q. (1990). Refugee welfare dependency: The trauma of resettlement. In W. H. Holtzman, \& W. H. Bornemann (Eds.), Mental health of immigrants and refugees (pp. 234-244). Austin, TX: Hogg Foundation for Mental Health.

Westermeyer, J. (1990). Motivations for uprooting and migration. In W.H. Holtzman, \& W. H. Bornemann (Eds.), Mental health of immigrants and refugees (pp. 78-89). Austin, TX: Hogg Foundation for Mental Health.

Ying, Y. (1 997). Psychotherapy for East Asians with major depression. In E. Lee (Ed.), Working with Asian Americans: A guide for clinicians (pp. 252-264). New York: Guilford Press. 